\title{
Secondary self-punitive behavior: Effects of periodic punishment of Sidman avoidance by a Pavlovian CS+
}

\author{
DAVE RIESS \\ Galesburg State Research Hospital, Galesburg, Ill. 61401
}

\begin{abstract}
Seven naive rats were trained on Sidman avoidance. Following adaptation to 3-sec response-contingent light presentations, Ss received alternate days of VI 3 -sec classical conditioning in which the light was paired with shock. During testing, the unreinforced light CS was response produced during short periods of the avoidance sessions. Acceleration of avoidance ("secondary" self-punitive behavior) resulted during these periods, Pavlovian extinction resulted in its rapid attenuation, and Pavlovian reconditioning produced immediate recovery. An interresponse time analysis of the secondary punishment periods revealed that mean IRTs increase linearly as a function of the number of previously punished responses, suggesting that the phenomenon is sufficiently delicate that response suppression would probably result if the punishment periods were prolonged.
\end{abstract}

A recent review of two-factor learning (Rescorla \& Solomon, 1967) summarizes the results of research exploring the effects of various Pavlovian stimuli on operant behavior. In nearly all of these studies, however, the Pavlovian stimuli are independent of the operant response. Little research has been done on the numerous possible ways of making the occurrence of such stimuli dependent upon the operant response. One possible relationship of interest would be to make the occurrence of such stimuli response-contingent. This has recently been attempted by Rescorla (1969) and Weisman \& Litner (1969) for an avoidance-contingent $\mathrm{CS}-$ and both studies demonstrated an increase in avoidance rates. In the case of the avoidance-contingent $\mathrm{CS}+$, Grossen \& Bolles (1968) showed that the interresponse time (IRT) subsequent to a response-contingent $\mathrm{CS}^{+}$was shortened on a VR 10 secondary punishment schedule during Sidman avoidance extinction, and Bender (1969) has shown that an avoidance-contingent Pavlovian CSt will increase resistance to extinction in a discrete trial situation. The present study attempts to determine the effects of an unreinforced CSt on maintained Sidman avoidance during periodic secondary punishment. There are several possible outcomes for this experiment predictable from related literature. The response contingency as such might prove irrelevant or at least secondary to the simple presence of the Pavlovian stimuli, in which case the result should be in the direction of acceleration as reported for noncontingent Pavlovian CS+s (Martin \& Riess, 1969, Rescorla, 1966; Riess, 1969; Riess \& Martin, 1969; Sidman, Herrnstein, \& Conrad, 1957). If the prediction is based on the analogy with studies of primary punishment of avoidance, one could predict either acceleration (Brown, 1969; Sandler, 1964) from the discrete trial literature, or suppression (McCullough, Shuman, \& McIntire, 1969; Mclntire, Davis, Cohen, \& Franch, 1968; Powell \& Morris, 1969) from the free operant literature. If the analogy were drawn with secondary punishment of appetitive behavior, suppression should result (Hake \& Azrin, 1965).

\section{SUBJECTS}

The Ss were seven naive Wistar albinos taken from the colony maintained by the Galesburg State Research Hospital Psychology Laboratory. The first (pilot) S was a male reared under normal laboratory conditions. The last six were females reared in an enriched environment described previously (Riess \& Plaut, 1970). All seven were moved to individual cages between 72 and 80 days of age, when experimentation began.

\section{APPARATUS}

The apparatus consisted of a modified Lehigh-Valley plastic shuttlebox, a Grason-Stadler shock generator and scrambler, white-noise generator, air-circulation fan, and sound-attenuation chest described previously (Riess \& Bath, 1970). A $7 \frac{1}{2}-\mathrm{W}$ white light in the sound chest ceiling provided illumination and two 60-W red lights served as the C.S.

\section{PROCEDURE}

The six female Ss were run through the following three-step sequence before testing began.

(1) Sidman avoidance acquisition consisted of nine daily 30 -min sessions with $\mathrm{RS}=30 \mathrm{sec}, \mathrm{SS}=5 \mathrm{sec}$, and shock $=.15 \mathrm{sec}, 1.6 \mathrm{~mA}$. Females raised in an enriched environment and trained in a shuttlebox reach an efficient and stable hurdle-cross pattern in a remarkably short period of time (Riess, 1970; Riess \& Plaut, 1970), normally avoiding over $95 \%$ of the shocks before an hour of training is completed.

(2) Adaptation was identical to Step 1, except that $3-\mathrm{sec}$ red-light presentations were made response-contingent for all responding during the 10 th, 15 th, 20 th, 25 th, and 30 th min of the session. In cases of interresponse times of less than $3 \mathrm{sec}$, the CS went off and then on immediately for another $3 \mathrm{sec}$, although this proved to be a relatively infrequent occurrence. The very short light duration was selected so that its offset would normally precede the subsequent avoidance response and thus minimize the possibility of superstitious reinforcement of responding (during testing) by having it adventitiously terminate after a response. A rate change ratio was computed from the formula $2 \mathrm{~B} /(\mathrm{A}+2 \mathrm{~B})$, where $\mathrm{A}$ (baseline) $=$ responding during the 120 -sec pre-CS periods and $\mathrm{B}=$ responding during the 1 -min periods with the CS+ contingency. Ss were required to have a 2-consecutive-day average of between .475 and .525 before proceeding.

(3) Classical conditioning consisted of eight coterminous light-shock pairings per session. The intertrial interval (ITI) was variable with three randomized values of 30 and $90 \mathrm{sec}$ and two values of $60 \mathrm{sec}$. The CS-US interval was variable with three randomized values of 1 and $5 \mathrm{sec}$ and two values of $3 \mathrm{sec}$. The US was a .15-sec 4-mA shock. The Pavlovian pairings were administered while $S$ was confined to one side of the shuttlebox by a transparent plastic barrier, and the side of confinement was alternated on successive sessions. Avoidance was continued on alternate days because uninterrupted sessions of inescapable shocks would otherwise disrupt performance.

(4a) Testing was begun after two classical conditioning sessions and was identical to Step 2. The classical conditioning continued on alternate days. This continued for 4 test days.

(4b) Ss were run an additional 4 days (4b), with the punishment periods reduced to the first $40 \mathrm{sec}$ of the 10th, 20th, and 30th min. The formula was adjusted to $3 \mathrm{~B} /(\mathrm{A}+3 \mathrm{~B})$.

(5) Pavlovian extinction was begun on alternate days after eight test sessions and was identical to Step 3 except that the light went unreinforced. Testing was continued on alternate days (as in $4 \mathrm{~b}$ ) until Ss met an extinction criterion identical to that for adaptation.

(6) Pavlovian reconditioning was identical to Step 3 and was followed by a single test session.

The single male (pilot) $S$ was treated identically except that (1) 18 avoidance 


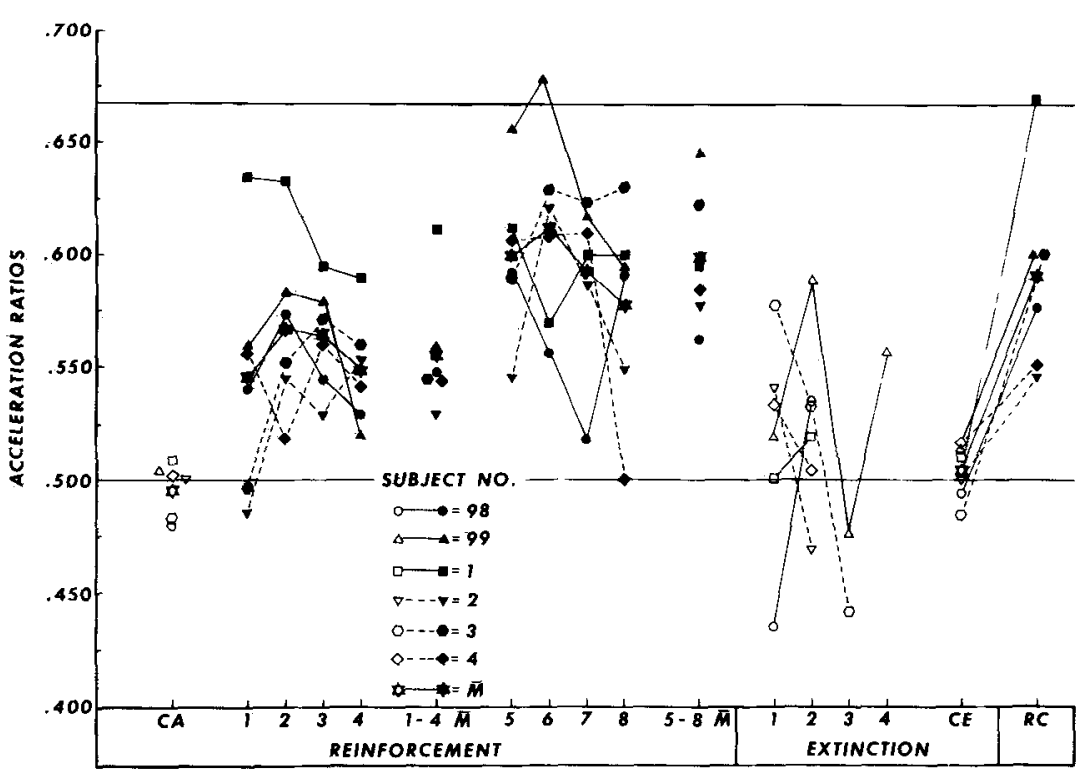

Fig. 1. Effects of an unreinforced response-contingent Pavlovian CS+ on avoidance behavior. Closed figures indicate the light was reinforced in previous classical conditioning sessions. .500 indicates no change in rates, .667 indicates a doubling of rate.

sessions were used with shock set at $1 \mathrm{~mA}$; (2) adaptation and test intervals were the 9th, 10th, 19th, 20th, 29th, and 30th min and the rate-change ratio used a baseline of $4 \mathrm{~min}$; (3) the classical conditioning intensity was $1 \mathrm{~mA}$, and 32 pairings were administered prior to testing; and (4) Steps 5 and 6 were omitted.

\section{RESULTS AND DISCUSSION}

Adaptation proved a relatively routine matter, four of the six Ss reaching criterion on the first 2 days and the remaining two requiring only 1 additional day.

The major results are presented in Fig. 1,

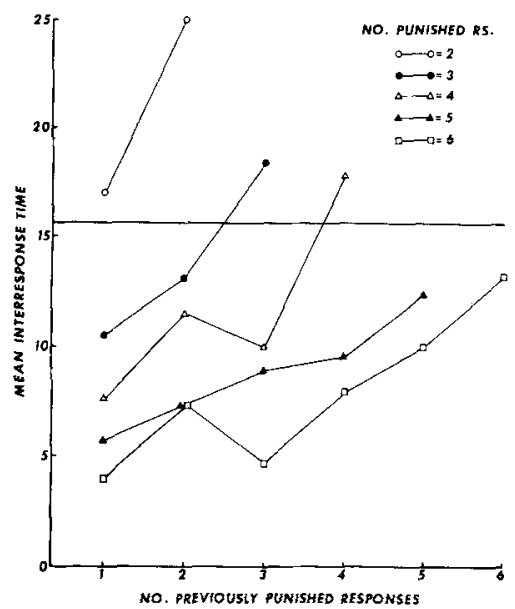

Fig. 2. Sequential IRTs as a function of the number of previously punished responses. The data are means for all six Ss. The horizontal line indicates the mean IRT for the baseline periods. for the second. Because of the tendency of repeated punishments to produce response patterns less indicative of acceleration and more suggestive of suppression, the second four test sessions were given to reduce the density of punishment and to record interresponse times (IRTs) following each punished response. Since the transition from a clearly accelerative to a more nearly suppressive pattern appeared to be a successive one, the IRT data from the punishment intervals was grouped on the basis of how many punished responses occurred and was then plotted as sequential IRT means. Inspection of Fig. 2 reveals a steady increase in $\bar{M}$ IRTs (and reciprocal reduction in response rate) as a function of the number of previously punished responses. This explains both the differences in the ratios for the first and second punishment minutes in the pilot $S$ and the jump in the ratios from Sessions 14 to $5-8$ in Fig. 1. It also suggests quite strongly that a response-contingent Pavlovian CS+ would act as a suppressor of avoidance behavior if longer periods of punishment had been used.

This rapid decrease in rates as a function of successive punishments can be seen even more dramatically by computing two mean IRTs for all of the punishment intervals, one for the time elapsing between the first punished response and the subsequent one and another for the last punished response and the subsequent one. The mean IRT is 8.8 following the first punished response and 16.9 following the last. Translated into pro rata acceleration ratios, this gives a .639 ratio (nearly double rate) for the first punished response and a .479 ratio (suppression) for the last.

One final occurrence of note is the IRT distribution inversions (i.e., the frequency of IRTs emitted is lowest around the mean during punishment, whereas it is highest during regular avoidance), which are skewed to the left. This is illustrated most dramatically in $S 1$, who made nine responses during his 11 th punishment interval and still managed to distribute them so inefficiently that he received a shock. The same $S$ made four responses during the 20th punishment interval and picked up both due shocks from separate R-S intervals. This highly scattered IRT pattern began to more closely resemble the normally distributed baseline distribution by the last four test sessions. Another related result was that, al though avoidance rates increased during the punishment periods, shock rates increased as well, a consistent finding due to the erratic IRT scatter.

\section{REFERENCES}

BENDER, L. Secondary punishment and 
self-punitive avoidance behavior. Joumal of Comparative \& Physiological Psychology, $1969,69,261-266$.

BROWN, J. S. Factors affecting self-punitive locomotor behavior. In B. A. Campbell and R. M. (hurch (1.ds.), Punishment and alersive behavior: New York: Appleton-C'entury. Crolts, 1969. Pp. 476-514.

GROSSI N, N. F.., \& BOLLES, R. C. I ffects of a classical conditioned 'fear signal' and 'safety signal' on nondiscriminated avoidance hehavior. Psychonomic Science, 1968, 11, 321-322.

HAKI , D. I., \& AZRIN, N. H. Conditioned punishment. Joumal of the Experimental Analysis of Behavior, 1965, 8, 279-293.

MARTIN, L. K., \& RIESS, D. Effects of UCS intensity during previous discrete delay conditioning on conditioned acceleration during avoidance extinction. Journal of Comparative \& Physiological Psychology, $1969,69,196-200$.

McClLlOUGH, T. A., SHUMAN, C. J., \& MiNTIRI:, R. W. lixed ratio punishment of free operant avoidance responding. Psychonomic Science, 1969, 17, 164-165.

MCINTIRE, R. W., DAVIS, H., COHEN, S. I., \& I RANCH, b. O. Sidman avoidance performance under punishment and noncontingent shock conditions. Psychological Reports, 1968, 22, 897-903.

POWELL, R. W., \& MORRIS, G. Continuous punishment of free-operant avoidance in the rat. Journal of the Experimental Analysis of Behavior, 1969, 12, 149-157.

RESCORLA, R. A. Predictability and number of pairings in Pavlovian fear conditioning. Psychonomic Science, 1966, 4, 383-384.

RESCORLA, R. A. Establishment of a positive reinforcer through contrast with shock. Journal of Comparative \& Physiological
Psychology, 1969, 67, 260-263.

RI:SCORIA, R. A., \& SOLOMON, R. L. Two-process learning theory: Relationships between Pavlovian conditioning and instrumental learning. Psychological Review, $1967,74,151-181$.

RIESS, D. Pavlovian phenomena in conditioned acceleration: Stimulus summation. Conditional Reflex, 1969, 4, 257-264.

RIESS, D. Shuttleboxes, Skinner boxes, and Sidman avoidance: Acquisition and terminal performance as a function of response topography. Manuscript available from Psychology Department, Galesburg (Ill.) State Research Hospital, 1970.

RIESS, D., \& BATH, J. Operant and Pavlovian stimulus control of avoidance latencies in conditioned acceleration. Psychonomic Science, 1970, 19, 165-167.

RIESS, D., \& MARTIN, L. K. Effects of UCS intensity during continuing coterminous delay conditioning on conditioned acceleration during maintained avoidance. Psychonomic Science, 1969, 16, 251-252.

RIESS, D., \& PLAUT, S, M. Sidman avoidance acquisition as a function of $\operatorname{sex}$ and enriched environment. Manuscript available from Psychology Department, Galesburg (Ill.) State Research Hospital, 1970.

SANDLER, J. Masochism: An empirical analysis. Psychological Bulletin, 1964, 62, 197-204.

SIDMAN, M., HERRNSTEIN, R. J., \& CONRAD, D. G. Maintenance of avoidance behavior by unavoidable shocks. Journal of Comparative \& Physiological Psychology, 1957, 50, 553-557.

WE.ISMAN, R. G., \& LITNER, J. S. Positive conditioned reinforcement of Sidman avoidance behavior in rats. Journal of Comparative \& Physiological Psychology, $1969,68,597-603$.

\title{
Effects of a Pavlovian conditioned fear stimulus on avoidance performance attenuated
} by experimental extinction

\author{
DENNIS K. KAMANO \\ Galesburg State Research Hospital, Galesburg, Ill. 61401
}

This study explored the effects on avoidance responding of superimposing a fear stimulus (CSt) after the avoidance response had been inhibited by experimental extinction. The CSt, established by coterminous delay conditioning, enhanced the response rate when presented either early in the extinction process or after completion of it. The same result was obtained for enhancement of response rate following CS+ offset.

It has been demonstrated repeatedly that a stimulus (CS+) consistently paired with an aversive US (Pavlovian fear conditioning) acquires an excitatory function, i.e., when presented during Sidman avoidance sessions, it will raise response rate. The present study is concerned with the effects of presenting such a CSt on avoidance behavior, but after the avoidance response had been inhibited by experimental extinction. An earlier research by Kamano ${ }^{1}$ had explored the effects of presenting a CS+, established by coterminous delay conditioning, during avoidance-response extinction. Superimposing the CSt early in extinction enhanced the response rate, as expected, but, more surprisingly, as extinction proceeded to a "leveling-off" point, the CSt continued to enhance the response rate. In addition, CS+ offset also enhanced the response rate throughout the entire extinction process.

In the present study the CSt was presented after extinction of shuttlebox avoidance had been completed, i.e., after avoidance response had been extinguished to pretraining hurdle-crossing level. We were concerned with whether or not the CSt was capable of eliciting an "extinguished" avoidance response.

\section{SUBJECTS}

Ss were three naive 65-day-old male Wistar albino rats from the colony maintained at the Galesburg State Research Hospital, and were housed in individual cages throughout the experiment.

APPARATUS

The apparatus was a modified Mowrer-Miller shuttlebox with a 10.16-cm-high hurdle and a drop gate which, when lowered, prevented hurdle crossing. A 10-W light bulb mounted above each compartment served as the CS, and shock was delivered through a grid floor. Details of the apparatus and shock source are described elsewhere (Kamano, 1968).

\section{PROCEDURE}

Pretraining

Ss were previously handled and, prior to experimental training, each $S$ received one 30-min session per day in the shuttlebox over the 2 consecutive days to determine the operant rate for hurdle crossing. Avoidance Training

Immediately following pretraining, Ss received shuttlebox avoidance training on a Sidman avoidance schedule with a shock-shock interval of $5 \mathrm{sec}$, a response-shock interval of $30 \mathrm{sec}$, and a shock intensity of $\mathbf{4 5 0}$ microamperes. One 30-min avoidance training session per day was given until performance had stabilized to a level where $S$ received no more than six shocks per session over 2 consecutive days.

\section{Pavlovian Conditioning}

After reaching the avoidance-training criterion, each $\mathbf{S}$ was given five Pavlovian conditioning sessions with avoidance training continuing on alternate days. The Pavlovian sessions were presented altemately on the two sides of the shuttlebox, and each session consisted of six trials with a mean intertrial interval of $2 \mathrm{~min}$ (range, 1.5-2.5 min). Six light CSs (two each) of 10,20 , or $30 \mathrm{sec}$ duration, coterminous with a standard 5-sec 450-microampere shock, were presented during each session

Pavlovian Conditioning

and Avoidance Extinction

The above phase was then followed by a series of avoidance extinction sessions (i.e., the avoidance contingencies were not in effect) with Pavlovian conditioning continuing on alternate days. The $30-\mathrm{sec}$ unreinforced $\mathrm{CS}+$ were presented during 